\title{
NIGHTM ARES WITHOUT ATONIA AS AN EARLY SYMPTOM OF DIFFUSE LEWY BODIES DISEASE
}

\author{
Paulo Roberto de Brito-Marques ${ }^{1}$, Roberto Vieira de Mello ${ }^{1,2}$, Luciano Montenegro ${ }^{1,2}$
}

\begin{abstract}
A male 70 years old patient with diffuse or "pure" Lewy body disease is described. The diagnosis was made based on clinical features of nightmares with no atonia, attention deficits with fluctuation in cognitive function, incapacity to find his way around the neighbourhood and other formerly familiar environments and mild neuropsychiatric symptoms. Neuropsychological assessment showed memory deficits, visuospatial and visuo-constructive disturbances. He had neither parkinsonism nor recurrent visual hallucinations typically well formed and detailled. Neuroimaging (computed tomography and magnetic resonance spectroscopy) showed mild diffuse cortical atrophy, mostly on the left temporal lobe and a decrease of $\mathrm{N}$ acetil-aspartate levels. A cholinesterase inhibitor was prescribed to this patient during 6 months with clinically relevant behavioral effect. Diagnosis confirmation was made by post-mortem neuropathological findings. Macroscopical features were mild atrophy on the frontal, parietal and temporal lobes, notedly on the frontal lobes. Microscopically, there was neuronal loss and diffuse classic Lewy bodies. Brainstem (substantia nigra, raphe nucleus, locus coeruleus, pedunculopontine nucleus), limbic cortex, and neocortex (frontal, parietal and temporal) were the areas of predilection for Lewy bodies. Hematoxylin-eosin and Bielschowsky staining did not show neuronal swelling (balooned cell), argyrophilic inclusion (Pick's bodies), neurofibrillary tangles nor senile plaques. Immunohistochemical staining for anti-tau, anti- $\beta$-amyloid, and anti-prion protein were negative. Antiubiquitine reaction was positive for Lewy body in the cerebral cortex and brainstem.
\end{abstract}

KEY WORDS: nightmares, extrapyramidal signs, visual hallucination, dementia, with Lewy bodies dementia.

\begin{abstract}
Pesadelos sem atonia como primeiro sintoma da doença difusa a corpos de Lewy
RESUMO - É descrito o caso de homem de 70 anos de idade com história progressiva, iniciada há 6 anos com pesadelos, problemas com a atenção ememória recente, dificuldade de encontrar lugares familiares e episódios de alucinação visual pouco elaborados. Na primeira avaliação neuropsicológica havia déficit difuso de leve intensidade, especialmente nas funções de atenção e memória, viso-espacial e viso-construtiva. Não houve sinais de parkinsonismo nem delírios recorrentes. Tomografia cerebral computadorizada mostrou atrofia cerebral própria da idade. Ressonância magnética com espectroscopia foi normal para faixa etária, embora houvesse redução na curva do $\mathrm{N}$-acetil-aspartato. $\mathrm{O}$ uso de um inibidor colinesterásico durante 6 meses melhorou sua autonomia cognitiva, comportamento e sono. Os achados de necrópsia evidenciaram atrofia cortical nas regiões fronto-parieto-temporais com maior acentuação nos lobos frontais. Do ponto de vista histopatológico, havia moderada quantidade de corpos de Lewy intracitoplamáticos distribuídos em todo o córtex cerebral, além de despovoamento neuronal com liberação pigmentar. As colorações por hematoxilina-eosina e Bielschowsky não revelaram células baloniformes, corpos de Pick, degeneração neurofibrilar e placa senil. Com exceção dos corpos de Lewy intracitoplasmáticos, as reações imuno-histoquimicas foram negativas para anti-ubiquitina, anti-tau, anti- $\beta$ amilóide, e proteína anti-prion.
\end{abstract}

PALAVRAS-CHAVE: pesadelos, sinais extrapiramidais, alucinação visual, demência, demência a corpos de Lewy.

Dementia with Lewy bodies (DLB) is a common form of dementia in the elderly. It accounts for 15$20 \%$ of cases of dementia in old age. Lewy bodies are intracytoplasmic, spherical, eosinophilic neuronal inclusion bodies ${ }^{1}$. Lewy body formation is central to the pathological phenotype of a spectrum of disorders ${ }^{2}$ as ataxia telangiectasia ${ }^{3}$, corticobasal de- generation ${ }^{4}$, Down's syndrome ${ }^{5}$, familial early-onset Alzheimer's disease $(A D)^{6}$, Hallervorden-Spatz disease $^{7}$, motor neuron disease ${ }^{8}$, multiple system atrophy ${ }^{9}$, neuroaxonal dystrophy ${ }^{10}$, progressive supranuclear palsy ${ }^{11}$, subacute sclerosing panencephalitis ${ }^{12}$. The most familiar of these disorders is the extrapyramidal syndrome of idiopathic Lewy-body Parkinson's

\footnotetext{
${ }^{1}$ Behavioral Neurology Unit, Department of Neurology, Faculty of Medical Sciences, University of Pernambuco, Recife PE, Brazil; ${ }^{2}$ Department of Pathology, Health Sciences Center, Federal University of Pernambuco, Recife PE, Brazil.

Received 13 January 2003, received in final form 6 June 2003. Accepted 3 July 2003.

Dr. Paulo Roberto de Brito-M arques - Rua Sport Clube do Receife 280/616 - 50070-450 Recife PE - Brasil. E-mail: pbrito@ truenet.com.br
} 
disease (PD) ${ }^{2}$. Studies of dementia in the elderly suggest that another disorder of Lewy body pathology is equally or even more common than PD. This syndrome of DLB has been named several diagnostic labels and is characterized by dementia, mild parkinsonism, visual hallucinations, and fluctuations of the consciousness. Although many of these features can be in PD, the patients with DLB tend to have early neuropsychiatric features which characterize the clinical picture, being the diagnosis of the syndrome in practice is concerned with the differential diagnosis of AD. The differential diagnosis of DLB disease has received increasing attention in the past few years in view of its potential therapeutic implications $^{1,2}$. For instance, nightmare that has not been included in consensus criteria for the clinical diagnosis of probable and possible dementia with Lewy bodies as a specific symptom ${ }^{1,13}$.

The report of this case is unique because nightmare was the first symptom found and it kept going through all the course of the disease, except during six months when the patient was treated with a cholinesterase inhibitor, rivastigmine.

\section{METHOD}

A diagnosis of possible Lewy bodies dementia was made in a male patient according to the criteria described by McKeith et al. ${ }^{1}$. The Clinical Dementia Rating (CDR) ${ }^{14}$ and Global Deterioration Scale (GDS) ${ }^{15}$ methods were used. Neuropsychological assessment was made on the basis of some items of Alzheimer's Disease Assessment Scale $(\mathrm{ADAS})^{16}$ and Mini-Mental State Examination (MMSE) ${ }^{17}$. The Carregiver Burden was used for measuring caregiver stress ${ }^{18}$. The patient was also submitted to neuroimaging studies such as computed tomography (CT) and spectroscopy magnetic resonance image (SMRI). The neurophatological examination was performed according to Consensus guidelines for the clinical and pathologic diagnosis of dementia with Lewy bodies ${ }^{1}$. The entire brain was fixed $10 \%$ formalin for 4 weeks prior cutting and it was cut into coronal sections. We examined 6-mm-thick paraffinembedded sections from the middle frontal, upper temporal, middle temporal, inferior parietal lobes, bilaterally, hyppocampus gyri, amygdaloid nuclei, and mesencephalon. They were routinely processed and stained with hematoxilin-eosin, and Bielschowsky methods. Immunohystochemical reactions with antibodies against tau, ubiquitine, $\beta$-amyloid were carried out.

\section{CASE}

A 70-year-old man right-handed, retired, without schooling, was admitted in Oswaldo Cruz University Hospital Pernambuco-Brazil, in January 1995. He began exhibiting excessive movement associated with nightmares with no atonia (NWNA) about 6 years prior to his first evaluation. One year before the first consult, the patient had an intestinal infection and he started to have visospatial disorder, some memory problems and attention deficits. During all course of the disease he had incapacity to find his way around the neighbourhood and other formerly familiar environments, mild visual hallucinations and jealousyepisodes with mild to moderate fluctuation in cognitive functions including situations of going blank.

During his NWNA he began exhibiting a behavior such as jumping out of the bed, shouting, and screaming. He was talkatived as if talking to imaginary people and presented many movements as a fight. Sometimes he fell from the bed on the floor or got up from bed to fight with the wall. The patient's wife used to wake him up and ask him what had happened. He when roused from sleep used to tell her his nightmares and he would soon fall back asleep again. Initially, these episodies occurred once or twice per month, and thereafter their frequency gradually increased. Excessive daytime sleepiness with episodes of confusion during wakefulness were presented and it was accentuated by a non stimulating environment. Personal and social functions and performance in daily living skills were markedly impaired in the early stages. The pattern of his memory impairment manifested itself as some difficulty in tasks with attentional requests. Memory of everyday life seemed to be impairmed. He hesitated about where he left some objects and ordinary daily events were not remembered, but some of his daily living activities were not impairmed. There werefluctuation in confusion and temporal desorientation episodies during all course of the disease, but the periodicity and magnitude of these events were variable. $\mathrm{He}$ was a previously efficient and independent truck driver. He never had any difficulties to drive anywhere as he always previously drived his truck all over Brazil. However, he was unable to find his way around the neighbourhood and other formerly familiar environments. He had a feeling he was stepping on an uneven surface. He had jealousy from his wife with any man. Sometimes he did not want his wife to leave their home to shop or other trivial things.

He was 165 centimeters tall and weighted $59 \mathrm{Kg}$. He did not have motor features of parkinsonism, syncopal attacks, repeated falls, transient losses of consciousness, systematized delusions and hallucinations. He used to drink alcoholic beverages (from 30 to 60 years of age on the weekend) and to smoke (from 15 to 55 years of age every day). The patient had no history of hypertension, diabetes and other 
Table 1. Clinical and Neuropsychological assessement with rivastigmine

\begin{tabular}{|c|c|c|c|c|}
\hline Domain & Tests & $\begin{array}{c}\text { Oct./98 } \\
\text { Score }\end{array}$ & $\begin{array}{c}\text { Jan./99 } \\
\text { Score }\end{array}$ & $\begin{array}{l}\text { Apr./99 } \\
\text { Score }\end{array}$ \\
\hline Language $^{16}$ & Oral naming & $2 / 12$ & $2 / 12$ & $2 / 12$ \\
\hline Visuospatial16 & Digit symbol & $\begin{array}{c}\text { Right } 0 \\
\text { Wrong } 1 \\
\text { Omission } 0\end{array}$ & $\begin{array}{c}\text { Right } 1 \\
\text { Wrong } 2 \\
\text { Omission } 3\end{array}$ & $\begin{array}{c}\text { Right } 0 \\
\text { Wrong } 1 \\
\text { Omission1 }\end{array}$ \\
\hline Gnosia $^{16}$ & Finger gnosia & $4 / 5$ & $2 / 5$ & $2 / 5$ \\
\hline Carregiver Burden ${ }^{18}$ & $\begin{array}{l}\text { Overload } \\
\text { Economic trains } \\
\text { Role capitivity }\end{array}$ & $\begin{array}{c}3,2,3,4 \\
3,3,2 \\
1,1,1\end{array}$ & $\begin{array}{c}1,1,1,1 \\
3,3,2 \\
1,1,1\end{array}$ & $\begin{array}{c}1,1,1,1 \\
3,3,2 \\
1,1,1\end{array}$ \\
\hline Screening ${ }^{17}$ & Mini Mental State Examination & $17 / 30$ & $22 / 30$ & $19 / 30$ \\
\hline Scale $^{15}$ & Global Deterioration Scale & $5 / 7$ & $4 / 7$ & $3 / 7$ \\
\hline
\end{tabular}

vascular risk factors. He did not use medications as beta blockers or L-dopa or neuroleptics during all disease course. His family history disclosed no dementing diseases and no psychiatric abnormalities emerged from his medical history.

The findings of the neurological examination 6 years after the onset of symptoms revealed a righthanded, attentive to the exam, cooperative and sensitive man. There were not pyramidal, extrapyramidal, or cerebellar signs. No peripheral neuropathy was found, and ocular movement was normal. He knew how to handle money very well, he could only write his name and make simple arithmetical operations. He was fully oriented in time and space and he had collaborated adequately during the test sessions. He obtained a score of 0,5 on the $\mathrm{CDR}^{16}$ and $19 / 30$ on the MMSE ${ }^{17}$. The patient used $1,5 \mathrm{mg}$ b.i.d ( $3 \mathrm{mg} /$ day) throught $6 \mathrm{mg}$ b.i.d ( $12 \mathrm{mg} /$ day) of rivastigmine during six months (Table 1 ).

Biochemical routine, hematological and sorological investigations were normal. Polysonographia evaluation was not done in this patient to confirm the clinical hypothesis of behavioral rapid-eye-moviment (REM) disorder. A CT obtained when he was 69 years old showed mild diffuse cortical atrophy, specially on the left temporal lobe. SMRI performed when he was 76 years old revealed diffuse cortical atrophy, mainly on the temporal lobes, being the left more atrophyc than the right. The hippocampi gyri were normal, specially when they were compared with the temporal lobes (Fig 1).

When the patient discontinued rivastigmine, he got a progressive worsening of the dementia, and about eighteen months after, he had a subacute subdural hematoma when he fell from his bed, during a nightmare. He underwent a neurosurgery and remained bedridden and all his personal needs were cared for by nursing personal at the Oswaldo Cruz University Hospital. He died at the age of 77, after a total clinical course of 12 years, from the first NWNA on, and 6 years from the first consult. His death on May $2^{\text {nd }} 2001$ was attributed to an infection. The clinical diagnosis was that of a possible dementia with Lewy's bodies.

Gross pathology. The postmortem interval was 14 hours. The brain weighed 1100 grams. The leptomeninges and cerebral arteries were normal. There was mild cortical atrophy on the frontal, parietal and temporal lobes, specially on the frontal lobes. Coronal sections revealed moderate dilatation of the medium ventricules. Midbrain sections showed mild pallor in the substantia nigra. There were no other gross abnormalities.

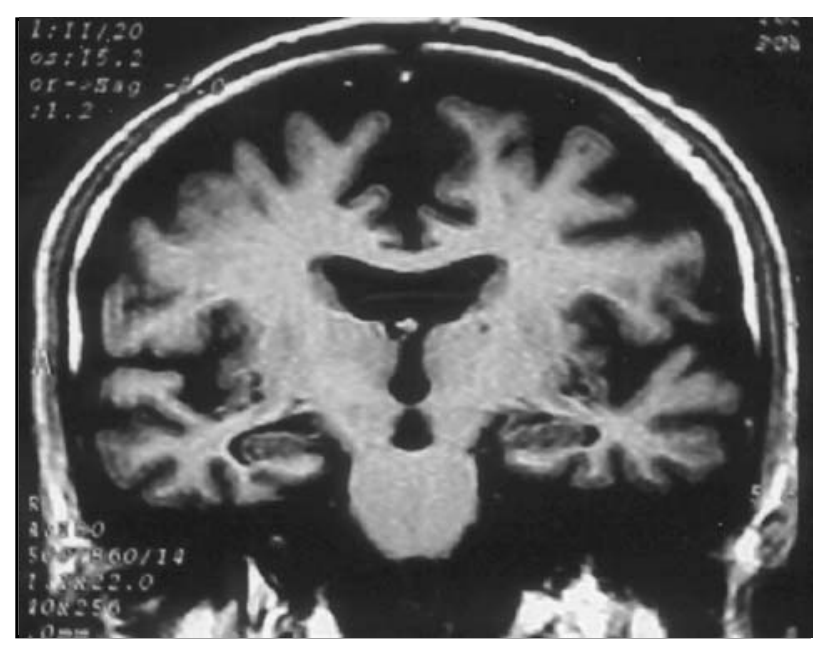

Fig 1. SMRI revealed diffuse cortical atrophy, mainly on the temporal lobes, being the left more atrophyc than the right. Hippocampal gyri were normal, specially when they were compared with the temporal lobes. 


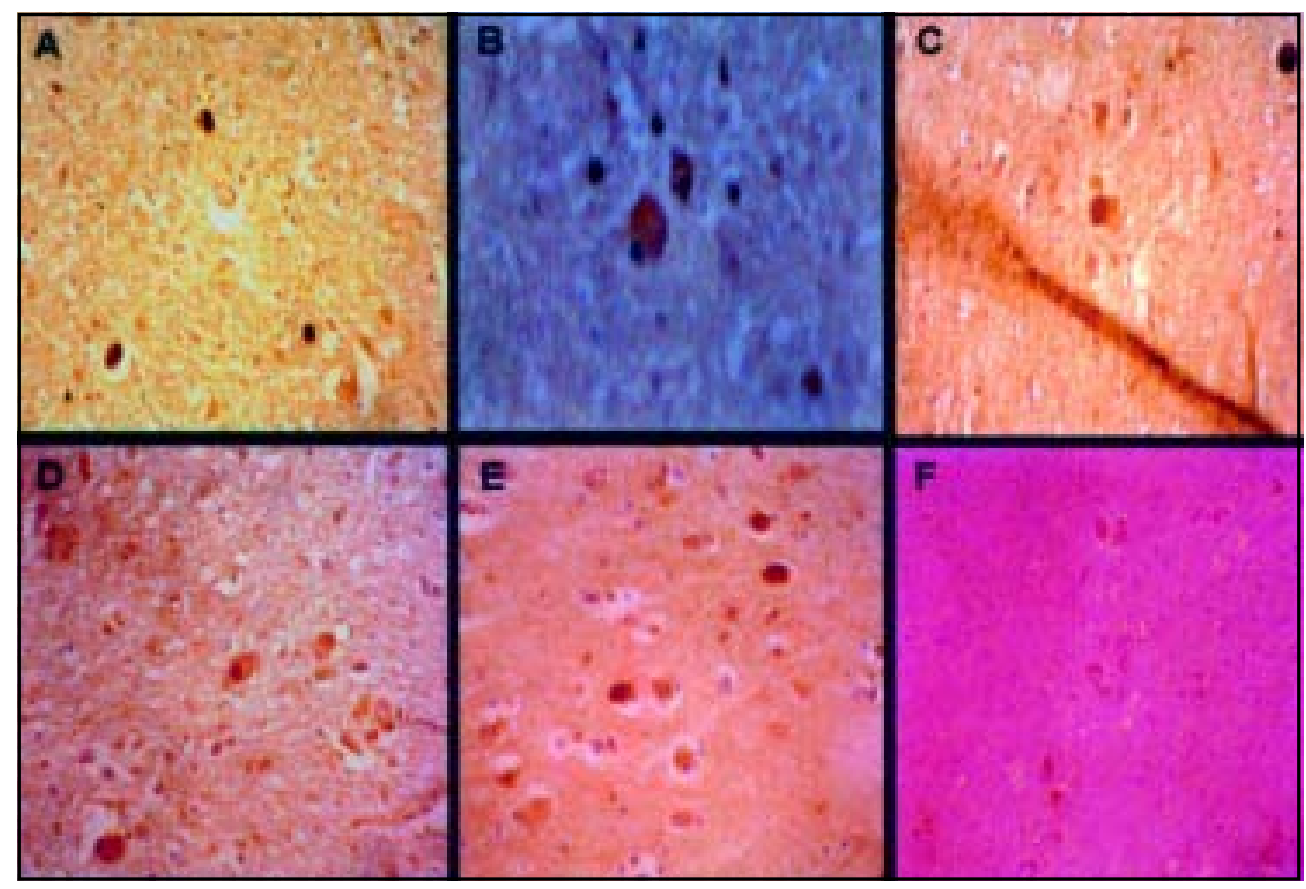

Fig 2. Immunohistochemistry with antiubiquitin reveals Lewy bodies and neuronal loss in pedunculopontine nucleus 100X (A), locus coeruleus 400X (B), basal nucleus of Meynert 100X (C), raphe dorsal nuclei 100X (D), and frontal lobe 100X (E). Hematoxylin and eosin stain of the substantia nigra 100X reveals Lewy bodies and neuronal loss too $(\mathrm{F})$.

Microscopic pathology. Brain sections were stained with hematoxylin and eosin, Bielschowsky, and immunocytochemically for antiubiquitine, antitau and anti- $\beta$-amyloid protein. Examination of middle frontal gyrus, superior and middle temporal, inferior parietal gyri, hyppocampi, amygdaloid nuclei and mesecephalon sections revealed moderate amount of intracitoplasmic Lewy bodies and neuronal loss. Examination of the pedunculopontine nuclei, locus coeruleus, basal nucleus of Meynert, raphe dorsal nuclei, and substantia nigra showed Lewy bodies and also neuronal loss (Fig 2). Hematoxylin-eosin (HE) and silver stains did not show neuronal swelling (balooned cell or Pick's cells), argyrophilic inclusion (Pick's bodies), neurofibrillary tangles, and senile plaques. Immunohistochemical staining for antibodies against tau, and $\beta$-amyloid were tested negative. There were also important release of lipofuscin and anoxia signs in the great pyramidal neurons. No focal white matter lesions or vascular disease were observed. Definitive diagnostic was diffuse Lewy body disease.

\section{DISCUSSION}

This case was based on the supposition that NWNA was a specific symptom for the clinical diagnosis of probable and possible diffuse Lewy bodies disease (DLBD). The antemortem features used in classifying such patients with dementing illnesses have not included phenomena reflecting brainstem alterations, that may occur several years before the development of neurodegenerativesigns. The patient's wife related methat following more than 6-year history suggestive of NWNA, the clinical features shifted to progressive cognitive deficit with mild spontaneous visual hallucinations, and notedly progressive fluctuation in cognition. He did not have parkinsonism. According to Barraquer y Bordas ${ }^{19}$, the practice of polisonographic recordings allows to identify loss of muscle atonia, as well as the motor complex activities that identify the impaired subject, whilethe bioelectrical desyncronization and R.E.M persist. On the other hand, a careful medical interview with the affected subjects with that syndrome made possible to recognize the correspondence, the link, between the dream content, usually full of angst, fear, and also agressivity, and the behavior, mostly destructive of the subject in contemporary parasomnia: socks, kicks, strangling and fleeing etc, as observed in this case.

Rivastigmine was used as treatment for this disease with good clinical response. Post-mortem examination of the limbic cortex, neocortex (frontal, parietal and temporal) and midbrain (locus coeruleus and substantia nigra) and brainstem (raphe, pedunculopontine and Meynert nuclei) showed loss of neurons and the presence of Lewy bodies. These clinical 
and pathologic changes were also found in the five cases published of REM sleep behavior disorder20-23. The Second International Workshop on DLB recommended that the Consensus criteria should continue to be used in its current format, the only modification being the addition of REM sleep behavior disorder and depression to the list of additional features "supportive" of this diagnosis ${ }^{13}$. Possibly there is a clinical and pathological relation between the NWNA symptom and the DLBD. Additional clinical features of DLBD, NWNA as specific clinical symptom, may improve the premortem diagnostic sensitivity, specificity, and predictive value of published criteria.

The physiologic mechanisms governing non-rapid eye movement (NREM) and REM sleep lie in the pontine reticular formation, as parts of the ascending reticular activating system. Cholinergic and aminergics neurons interact with the pedunculopontine nuclei and the medial pontine reticular formation (dorsal nucleus of raphe). Therefore, lesions of the raphe nuclei, substantia nigra and mainly locus coeruleus decrease of monoamine levels and increase the REM activity by inhibiting cholinergic neurons in the pedunculopontine nucleus mediating atonia during REM sleep ${ }^{20,24}$. Early accurate clinical diagnosis of DLBD is particularly important to manage issue such as avoiding severe neuroleptic sensitivity reactions, achieving the optimal level of antiparkinsonian treatment without exacerbating psychiatric symptoms, and a possible beneficial response to cholinesterase inhibitors ${ }^{25}$. Therefore, additional clinical features of DLBD may improve the premorbid diagnostic sensitivity, specifivity, and predictive value of published criteria as this case.

The autopsy showed cortical Lewy bodies that were less well circumscribed and difficult to recognize using conventional staining methods, but readily visualized with antiubiquitine immunocytochemical detection. The areas of prediletion for Lewy bodies on the coronal slices through human brain depicting Brodmann areas were frontal (middle frontal giry 8/9), temporal (superior temporal giry 22), temporal (middle temporal gyri 21), parietal (inferior parietal lobule 40), hippocampy gyri, amygdaloid nuclei, and locus coeruleus $^{26}$. Besides these Brodmann areas there were also Lewy bodies in Meynert, raphe, locus coeruleus and pedunculopontine group nuclei in our case.

Many deficits in cholinergic neurotransmission are seen in patient brains with Lewy body dementia. They are probably secondary to presynaptic depletion in brainstem and basal forebrain cholinergic nuclei, with more preservation of postsynaptic mechanisms than seen in $A D^{26}$. Therefore, drugs enhancing central cholinergic function represent a rationally-based therapeutic approach to this disorder ${ }^{26}$. Carbacol or glutamate-mediated excitation of cholinergic neurons in the pedunculopontine nucleus induces REM sleep, and acetylcholinesterase inhibitors decrease REM sleep latency and increase REM sleep duration ${ }^{20}$. It is possible that this patient had a significant neurobehavioral improvement with rivastigmine, and his clinical improvement might be related to a cholinergic interaction between the locus coeruleus and the raphe nuclei, and the pedunculopontine nuclei ${ }^{24}$.

Neuropsychologic tests reveal deficit profile of deficits that help to identify DLBD ${ }^{27}$. Visuospatial disturbances were the most found frequently symptoms in our patient both in relation to the medical report and the objective clinical assessements. It was shown that these error types were a manifestation of visuospatial deficit, revealing a major problem of the DLBD: the spatial organization. There were not important significant changes in the language tests while the neuropsychological tests were improved on the MMSE ${ }^{17}, \mathrm{GDS}^{15}$, Caregiver Burden ${ }^{18}$. This patient also presented even greater improvement of the nightmares, personal and social function and daily living skills performance and in other cognitive and neuropsychiatric symptoms as well, when he was treated with a cholinestearase inhibitor. Approximately $10 \%$ of the DLB population appear to be homozygous to the butyrylcholisterase K locus compared to only 1 or $2 \%$ in the AD group, so that this genetic risk factor seems to distinguish the two diseases ${ }^{2}$. This finding may be relevant to the hypotesis that DLB cases are more likely to respond to cholinergic therapy than $A D^{2}$. When the patient discontinued rivastigmine, he got a progressive worsening of the dementia. Deficits in memory, language, and other cognitive skills overlap with those seen in a severe primary dementia, by a combination of cognitive and neurologic disability. During a nightmare the patient had cranio-cerebral trauma and had a subacute subdural hematoma. He underwent a surgery and re mained bedridden and all his personal needs were cared for by the nursing personal at the Oswaldo Cruz University Hospital.

In conclusion we suggest that, (i) idiopathic NWNA with comorbid DLBD may be a manifestation of the same neurodegenerative process, (ii) fluctuation was considered mandatory as a clinical characteristic for this diagnosis, (iii) the most sensitive neuropsychologic tests can contribute to the characterization of possible qualitative differences bet- 
ween the DLBD versus other brain pathologies, (iv) rivastigmine, a cholinesterase inhibitor, may be used as a therapeutic approach in patients with possible DLBD, (v) the presence of Lewy bodies in the locus coeruleus, substantia nigra, raphe nucleus and specially in the pedunculopontine nucleus may be involved with the of NWNA mechanism, (vi) the occurrence of Lewy bodies in the neocortexand basal nucleus of Meynert may play an important role in the pathogenesis of cognitive and memory disturbances, respectively, and (vii) the diffuse Lewy body disease is a nosologic entity. Future developments in clinical classification of the dementias should take these considerations on account.

Acknowledgment - The authors acknowledge the contribution of the patient and his family for this article. The authors thankAna Paula De Biase Mulatinho, occupational therapist at Behavioral Neurology Unit - Research on Alzheimer's Disease and Related Disorder.

\section{REFERENCES}

1. McKeith IG, Galasko D, Kosaka K, et al. Consensus guidelines for the clinical and pathologic diagnosis of dementia with Lewy bodies (DLB): report of the consortium on DLB international workshop. Neurology 1996;47:1113-1124.

2. Ince PG, Perry EK, Morris CM. Dementia with Lewy body: a distinct non- Alzheimer dementia syndrome? Brain Pathol 1998;8:299-324.

3. DeLeon G, Grover W, Huff D. Neuropathological changes in ataxiatelangiectasia. Neurology 1976;26:947-951.

4. Horoupian D, Chu P. Usual case of corticobasal degeneration with tau/ Gallyas -positive neuronal and glial tangles. Acta Neuropathol 1994;82:592-598.

5. Bodhireddy S, Dickson DW, Mattiace L, Weidenheim KM. A case of Down's syndrome with diffuse Lewy body disease and Alzheimer's disease. Neurology 1994;44:159-161.

6. Lantos PL, Ovenstone IM, Johnson J, Clelland CA, Roques P, Rossor MN. Lewy bodies in brains of two members of a family with the 717 (Val to Lle) mutation of the amyloid precursor protein gene. Neurosci Lett 1994;172:77-79.

7. Gaytan-Garcia S, Kaufmann JC, Young G. Adult onset Hallervoden Spatz syndrome or Seitelberg's disease with late onset: variants of the same entity? a clinicopathological study. Clin Neuropathol 1990;9:136-142.
8. Williams T, Shaw PJ, Lowe J, Bates D, Ince PG. Parkinsonism in motor neuron disease: case report and literature review. Acta Neuropathol 1995;89:275-283.

9. Sima AA, Hoag G, Rozdilsky B. Shy-Drager syndrome: the transitional variant. Clin Neuropathol 1987;6:49-54.

10. Sugiyama H, Hainfeller JA, Schmid SB, Budka H. Neuraxonal dystrophy combined with diffuse Lewy body disease in a young adult. Clin Neuropathol 1993;12:147-152.

11. Mori H, Yoshimura M, Tomonaga M, Yamanouchi H. Progressive supranuclear palsy with Lewy bodies. Acta Neuropathol 1986;71:344-346.

12. Gibb WRG, Scaravilli F, Michaud J. Lewy bodies and subacute sclerosing panencephalitis. J Neurol Neurosurg Psychiatry 1990;53:710-711.

13. McKeith I, Perry EK, Perry RH. Diagnosis and treatment of dementia with Lewy bodies (DLB): report of the second DLB International Workshop. Neurology 1999;53:902-905.

14. Hughes CP, Berg L, Danziger WL, et al. A new clinical scale for the staining of dementia. Br J Psychiatry 1982;140:566-72.

15. Reisberg B, Ferris SH, Leon MJ. The global deterioration scale for assessment of primary degeneration dementia. Am J Psychiatry 1982;139:1136-1139.

16. Rosen WG, Mohs RC, Davis KL. A new rating scale for Alzheimer's disease. Am J Psychiatry 1984;141:1356-1364.

17. Folstein MF, Folstein SE, McHugh PR. Mini-mental state: a pratical method for grading the cognitive state of patients for the clinician. J Psychiatr Res 1975; 12:189-98.

18. Pearlin Li, Mullan JT, Semple SJ, Skaff MM. Caregivving and the stress: an overview of concepts and their measures. Gerontologist 1990;583-594.

19. Barraquer i Bordas L. Las pesadillas y la "actuación conductual" durante el sueño REM. Neurología 2001;16:214-220.

20. Turner RS, D'Amato CJ, Chervin RD, Blaivas M. The pathology of REM sleep behavior disorder with comorbid Lewy body dementia. Neurology 2000;55:1730-1732.

21. Uchiyama M, Isse K, Tanaka K, et al. Incidental Lewy bodies disease in patient with REM sleep behavior disorder. Neurology 1995;45:709-712.

22. Boeve BF, Silber MH, Ferman TJ, et al. REM sleep behavior disorder and degenerative dementia. Neurology 1998;51:363-370.

23. Schench $\mathrm{CH}$, Mahowald MW, Anderson ML, et al. Lewy body variant of Alzheimer's disease (AD) identified by postmortem ubiquitin staining in a previously reported case of AD associated with REM sleep behavior disorder. Biol Psychiatry 1997;42:527-528.

24. Adams RD, Victor M. Principles of neurology. 7.Ed. New York: McGraw Hill, 2001;404-535.

25. McKeith I, Del Ser T, Spano PF, et al. Efficacy of rivastigmine in dementia with Lewy bodies: a randomised, double-blind, placebocontroled international study Lancet 2000;356:2031-2036.

26. Lennox G, Lowe J, Morrel R, et al. Anti-ubiquitin immunocytochemistry is more sensitive than conventional techniques in the detection of diffuse Lewy bodies disease. J Neurol Neurosurg Psychiatry 1989;52:67-71.

27. Gauthier L, Dehaut F, Joanette Y. The Bells test: a quantitative and qualitative test for visual neglet. Inter J. Clin Neuropsychol 1989;11:49-54. 